\title{
Development of Electrically Conductive Nanocrystalline Thin Film for Optoelectronic Applications
}

\author{
Sujan Kumar Das ${ }^{1, *}$, Jahid M. M. Islam ${ }^{3}$, Monirul Hasan ${ }^{2}$, Humayun Kabir $^{2}$, \\ Md. Abdul Gafur ${ }^{4}$, Enamul Hoque ${ }^{2}$, Mubarak A. Khan ${ }^{3}$ \\ ${ }^{1}$ Department of Physics, University of Chittagong, Chittagong - 4331, Bangladesh \\ ${ }^{2}$ Department of Physics, Jahangirnagar University, Savar, Dhaka - 1342, Bangladesh \\ ${ }^{3}$ Institute of Radiation and Polymer Technology, Bangladesh Atomic Energy Commission, \\ Dhaka - 1000, Bangladesh \\ ${ }^{4}$ Pilot Plant and Process Development Centre, Bangladesh Council of Scientific and Industrial \\ Research, Dhaka, Bangladesh \\ *E-mail address: skdas@cu.ac.bd
}

\begin{abstract}
Sodium alginate $\left(\mathrm{TiO}_{2}\right)$ sand composites were prepared by solution casting. Purified sand was added in the composite films to increase electrical conductivity. Electrical properties such as conductivity, capacitance, dielectric constant, and loss tangent of the composites were investigated. The current voltage characteristics for all the composites showed ohmic behavior. All the electrical properties have been found to improve with the incorporation of sand $\left(\mathrm{SiO}_{2}\right)$ but $6 \%$ sand containing composite exhibits the best electrical properties. The mechanical properties tensile strength (TS), elongation at break (Eb) and Young modulus for $6 \%$ sand containing composite film are found to be 4.445 MPa, 9.76 \%, and 72.8 MPa respectively. The experimental results reveal that the blended films exhibit higher stability and improved mechanical properties of both tensile strength and elongation at break in dry state. Water absorption properties of the composites are found to decrease with the increase of sand content. Lowest water uptake properties and highest stability were demonstrated by 6 $\%$ sand containing sample. Electrically conductive composite films have useful applications for solar cells and optoelectronics. Thus, this study is very much expected to aid in the design and selection of proper composite for the potential application of solar cell and optoelectronics
\end{abstract}

Keywords: Conductive thin film; Composite; $\mathrm{TiO}_{2}$; Solar cell; Optoelectronics; Sodium alginate

\section{INTRODUCTION}

Sodium alginate (chemical formula is $\mathrm{NaC}_{6} \mathrm{H}_{7} \mathrm{O}_{6}$ ) is an electro-active bio-polymer extracted from the cell walls of brown algae. Biopolymers are a special class of polymers either produced or synthesized from within living organisms [1]. Biopolymers are a renewable resource and have a wide range of uses in nature, functioning as energy storage, transport, signaling, and structural components. Sodium alginate has a versatile use in textile and printing industry as well as food industry. It is soluble in both hot and cold water and has the ability to form films. 


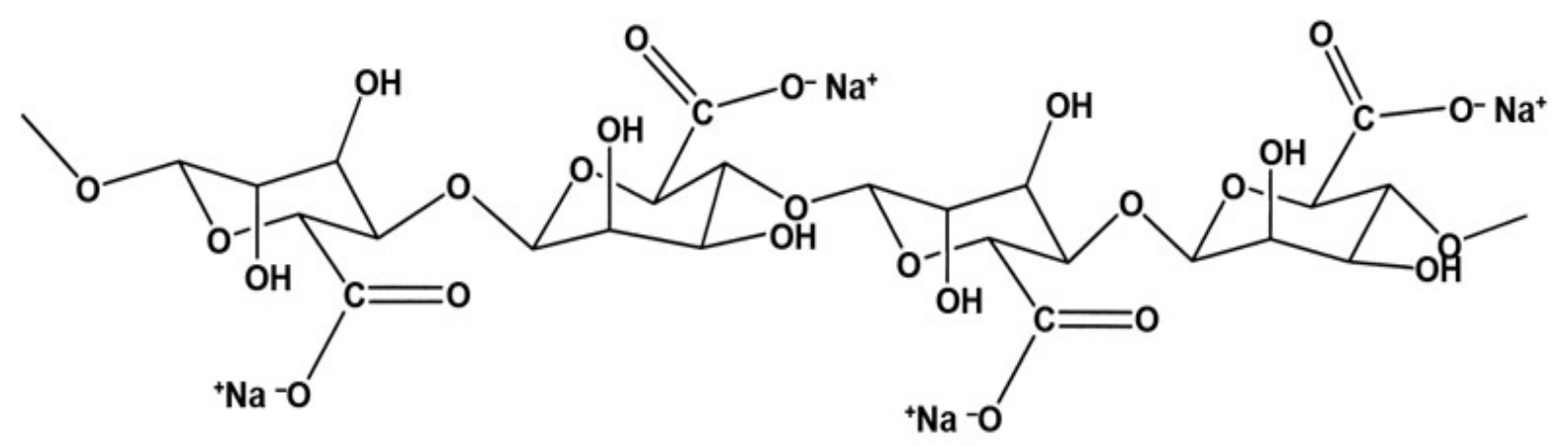

Sch. 1: Chemical structure of mannuronic acid-rich type of sodium alginate

$\mathrm{TiO}_{2}$, an inexpensive, non-toxic and biocompatible material, is one of the most interesting nanostructured photocatalysts [2-6] as it exhibits excellent optical, electrical, and thermal properties. The interest in $\mathrm{TiO}_{2}$ as a strategic material for environmental photocatalysis and photoelectrochemical solar energy conversion has continuously increased.

They are mainly related to photocatalysis, photovoltaic devices, dye-sensitized solar cells, sensors, paintings and potential tool in cancer treatment [7-12]. However, it is well known that there are two typical drawbacks in practical application. Firstly, only the ultraviolet part of the solar irradiation (amounting to $\sim 4 \%$ of the incoming solar energy on the earth's surface) could be absorbed by $\mathrm{TiO}_{2}$ due to its high intrinsic band gap $(3.2 \mathrm{eV}$ for anatase and 3.0 for rutile). Secondly, a low rate of electron transfer to oxygen and a high rate of recombination between excited electron-hole pairs result in a low quantum yield rate and also a limited photo-oxydation rate. In order to resolve the above listed problems, continuous efforts have been made to improve the properties of $\mathrm{TiO}_{2}$ thin film, for example, noble metal loading, metal ion doping, anion doping, dye sensitization, composite semiconductors, metal ion-implantation, etc. [13-17].

Silicon dioxide is one of the most commonly encountered substances in both daily life and in electronics manufacturing and is available in our nature. In this work the preparation of Na-alginate $\left(\mathrm{TiO}_{2}\right)$ sand thin films (of 0.1 to $10 \%$ sand content by weight) using solution casting method at room temperature is described in details. The electrical and mechanical properties of the films have been investigated using different instruments and methods.

\section{EXPERIMENTAL}

\section{1. Materials}

Sodium alginate $\left(\mathrm{NaC}_{6} \mathrm{H}_{7} \mathrm{O}_{6}\right)$ and titanium dioxide $\left(\mathrm{TiO}_{2}\right)$ were purchased from MERK, Germany. Sand $\left(\mathrm{SiO}_{2}\right)$ was collected from Sylhet, Bangladesh.

\section{2. Methods}

\subsection{Sand purification}

Collected sand contained various impurities was washed with $0.1 \%$ sulfuric acid $\left(\mathrm{H}_{2} \mathrm{SO}_{4}\right)$ for about 10 times. Then it was dried at room temperature for 24 hour. Again the sand was washed with $10 \%$ sulfuric acid and then dried. After drying it was again washed with distill water and finally dried at room temperature for 48 hour. Dried sand was then made 
into powder form firstly by grinding with mortar and then by ball milling with Universal Ball Mill (Model: UB-32, Yamato Scientific Co. Ltd., Japan). Finally sand $\left(\mathrm{SiO}_{2}\right)$ powder was filtered by filtering machine.

\section{2. 2. Preparation of formulations}

Sodium alginate was dissolved in distill water along with varying percentage of sand and titanium dioxide to prepare various formulations. Mixtures were stirred continuously to aid formation of homogeneous mixture and heated for about one and half an hour at $115^{\circ} \mathrm{C}$.

Then these formulations were sonicated by microwave sonicator for an hour. Table-1 showed six types of such formulations $\left(\mathrm{F}_{1}-\mathrm{F}_{6}\right)$.

Table 1. Composition of different formulations $(\%, w / w)$.

\begin{tabular}{|c|c|c|c|c|c|c|}
\hline \multirow{2}{*}{ Components } & \multicolumn{7}{|c|}{ Formulations } \\
\cline { 2 - 7 } & $\mathbf{F}_{\mathbf{1}}$ & $\mathbf{F}_{\mathbf{2}}$ & $\mathbf{F}_{\mathbf{3}}$ & $\mathbf{F}_{\mathbf{4}}$ & $\mathbf{F}_{\mathbf{5}}$ & $\mathbf{F}_{\mathbf{6}}$ \\
\hline $\mathrm{NaC}_{6} \mathrm{H}_{7} \mathrm{O}_{6}$ & 92 & 91.9 & 91.5 & 91 & 86 & 82 \\
\hline $\mathrm{TiO}_{2}$ & 8 & 8 & 8 & 8 & 8 & 8 \\
\hline Sand & 0 & 0.1 & 0.5 & 1 & 6 & 10 \\
\hline
\end{tabular}

\section{2. 3. Preparation of thin films}

The formulated solutions were cast on silicon paper (release paper) mounted on level glass plate. The solutions were kept at room temperature for about 72 hour. After formation of the films, they were peeled off and cut into a dimension of $100 \times 50 \mathrm{~mm}^{2}$. Average thickness of the films was 0.1 to $0.3 \mathrm{~mm}$.

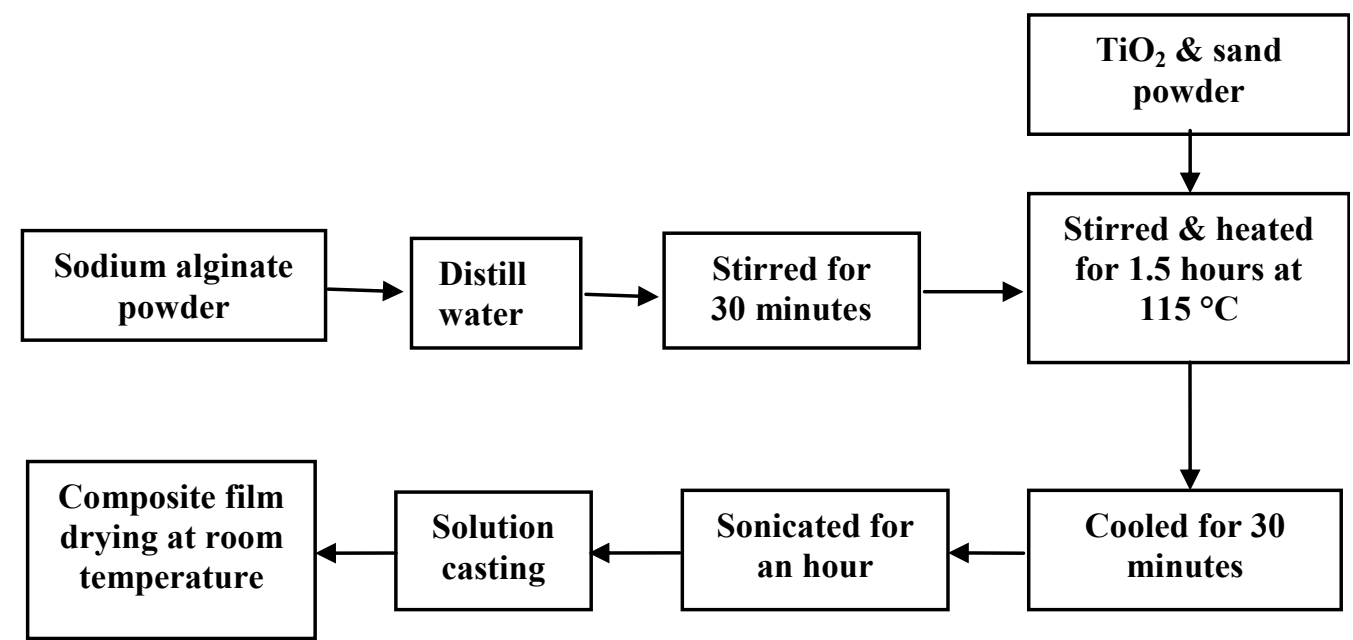

Flow Sheet 1. Preparation process of Na-alginate $\left(\mathrm{TiO}_{2}\right)$ sand thin film. 


\section{3. Properties measurement}

The samples were cut with an anti-cutter into small pieces of length $70 \mathrm{~mm}$ and width $30 \mathrm{~mm}$. These samples were stored in a laminated poly-ethylene bag at room temperature and $65 \%$ relative humidity until testing. All tests were carried out under similar condition.

\section{3. 1. Electrical Properties}

Samples were cut into square shape with edge of $1 \mathrm{~cm}$ and the two surfaces of each sample were coated with silver paste as contact material for electrical measurements. Silver paste was added on both sides of the samples together with two thin copper wires of 100micron diameter which were well polished by silicon paper to improve contacting for conduction. The samples were dried at $37{ }^{\circ} \mathrm{C}$ to eliminate any absorbed moisture. Then we add scostape over both sides the samples to make ready for taking electrical properties.

The resistivity $(\rho)$ of the samples was measured using the Agilent Precision Impedance Analyzer (Agilent, 4291a) and the conductivity $(\sigma)$ was calculated from the following relation

$$
\sigma=1 / \rho
$$

The dielectric loss and capacitance of the samples were measured at room temperature by Agilent 4263B LCR meter with frequency ranges from $100 \mathrm{~Hz}$ to $100 \mathrm{kHz}$. Dielectric constant of the samples were calculated from the measured capacitance using the following relation

$$
\varepsilon_{\mathrm{r}}=\mathrm{C} / \mathrm{C}_{\mathrm{o}}
$$

where $C$ and $C_{o}$ are the capacitance of the capacitor with samples and with air respectively. $C_{o}$ was calculated from the knowledge of the dimension of the samples using the following relation

$$
\mathrm{C}_{\mathrm{o}}=8.854 \times 10^{-12} \times \mathrm{A} / \mathrm{d}
$$

where $\mathrm{A}$ is the area of the capacitive cell in meter $^{2}$ and $\mathrm{d}$ is the thickness of the sample (or gap between the electrodes) in meter. A Keithley617 programmable electrometer, Keithley197A auto ranging micro voltmeter and a dc power supply were set in current-voltage mode for recording the current through the sample at different voltage at constant temperature and irradiation. In this case the voltage was varied from 0 to $32 \mathrm{~V}$ and the current was recorded every 2 volts intervals.

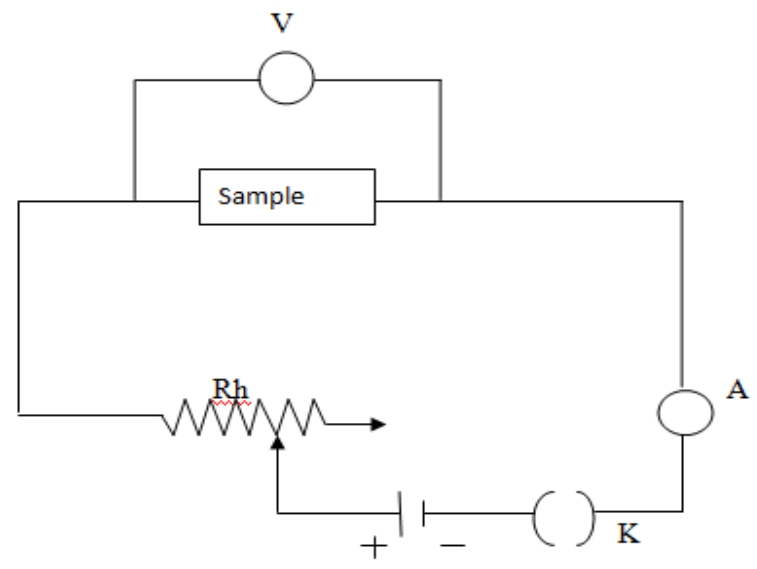

Fig. 1. Experimental circuit diagram for I-V measurement. 


\section{3. 2. Mechanical Properties}

Mechanical properties: Tensile Strength (TS), Elongation at break (Eb \%) and Young Modulus (E) of the films were measured with Universal Testing Machine (HOUNSFIELD, model H50KS). The test specimens were $70 \mathrm{~mm}$ in length and $10 \mathrm{~mm}$ in width. Parameters of the UTM for tensile properties measurements are given below:

Load range $=10 \mathrm{~N}$, extension range $=200 \mathrm{~mm}$, gauge length $=25 \mathrm{~mm}$, speed $=500$, approach Speed $=500$, pre-load $=0$

The test specimen was prepared according to ASTM Method [18] for measuring tensile strength.

$$
\begin{gathered}
\text { Tensile Strength (TS) }[19]=\frac{\text { Applied load }(F)}{\text { Cross sectional area of the load bearing area }(A)} \\
\text { i.e., TS }(\mathrm{MPa})=\frac{\text { Applied load }(\mathrm{N})}{\text { Width }(\mathrm{mm}) \times \operatorname{Thickness}(\mathrm{mm})} \text {.................... (4) }
\end{gathered}
$$

Elongation at break was calculated according to ASTM D-638 [20].

$$
\text { Elongation at break, Eb }(\%)=\frac{\text { Extention at break }}{\text { Gauge Length }} \times 100 \%
$$

The slope of the initial straight line portion of the stress-strain curve is the elastic modulus of a material. In a tensile test this modulus is Young's modulus and is calculated by

$$
\mathrm{E}=\frac{\mathrm{d} \sigma}{\mathrm{d} \varepsilon},
$$

where $\mathrm{d} \sigma=$ Stress at yield $\sigma_{\mathrm{y}}$ and $\mathrm{d} \varepsilon=$ Strain at yield $\varepsilon_{\mathrm{x}}$.

\section{3. 3. Water Uptake and Stability}

Water uptake and aging of the samples are taken for studying the stability of the samples with time [21]. The water intake specimens were prepared according to ASTM [22].

The test specimens were about $30 \mathrm{~mm}$ length, width about $15 \mathrm{~mm}$ and thickness about $0.180 \mathrm{~mm}$. The water uptake of the specimens was periodically monitored up to 80 seconds to find the profile of water uptake. Water absorption was measured using the following equation

$$
\mathrm{W}_{\mathrm{g}}=\frac{\mathrm{W}_{\mathrm{a}}-\mathrm{W}_{0}}{\mathrm{w}_{0}} \times 100 \%
$$

where:

$\mathrm{W}_{\mathrm{g}}=$ percentage of weight gained by the sample due to water absorption,

$\mathrm{W}_{\mathrm{a}}=$ weight of the sample after water treatment,

$\mathrm{W}_{0}=$ weight of the dry sample before water treatment. 


\section{RESULTS AND DISCUSSION}

Most of the data presented in this paper are average values of at least five samples and the results obtained are within the accuracy of $\pm 1 \%$.

\section{1. Electrical Properties Analysis}

\section{1. 1. Conductivity}

Frequency has an important influence on the electrical properties of $\mathrm{Na}$-alginate $\left(\mathrm{TiO}_{2}\right)$ sand composite. Fig. 2 shows the dependence of AC electrical conductivity on the frequency of the signal for different $\%$ wt sand containing composites. The conductivity increases with increase in frequencies until $13 \mathrm{MHz}$. This behavior is reasonable because the low frequency AC field is not sufficient to activate the charge carriers but with the increase in frequency their mobility increases yielding the increase in conductivity until $13 \mathrm{MHz}$. The deviation from the linearity at higher frequencies is likely due to the dispersion of molecules. Generally, the electrical conductivity of the polymer depends on the presence of free ions connected chemically with macromolecule. The molecular chain does not participate in the transfer of electrical charge [23]. Hydrogen bonded polymer usually have higher conductivity with respect to non-hydrogen bonded polymers. The tunneling model is applied in the mechanism of charge carriers at higher frequency which assumes that an electron in a molecular orbital of one molecule, when excited to a higher energy level, can tunnel through a potential barrier to an unoccupied state of a neighboring molecule keeping the energy conserved in the tunneling process [24]. Also, the conductivity increases with increase in frequency. The AC conductivity data of all sample used for this article agrees considerably with the available experimental results published in the literature [25].

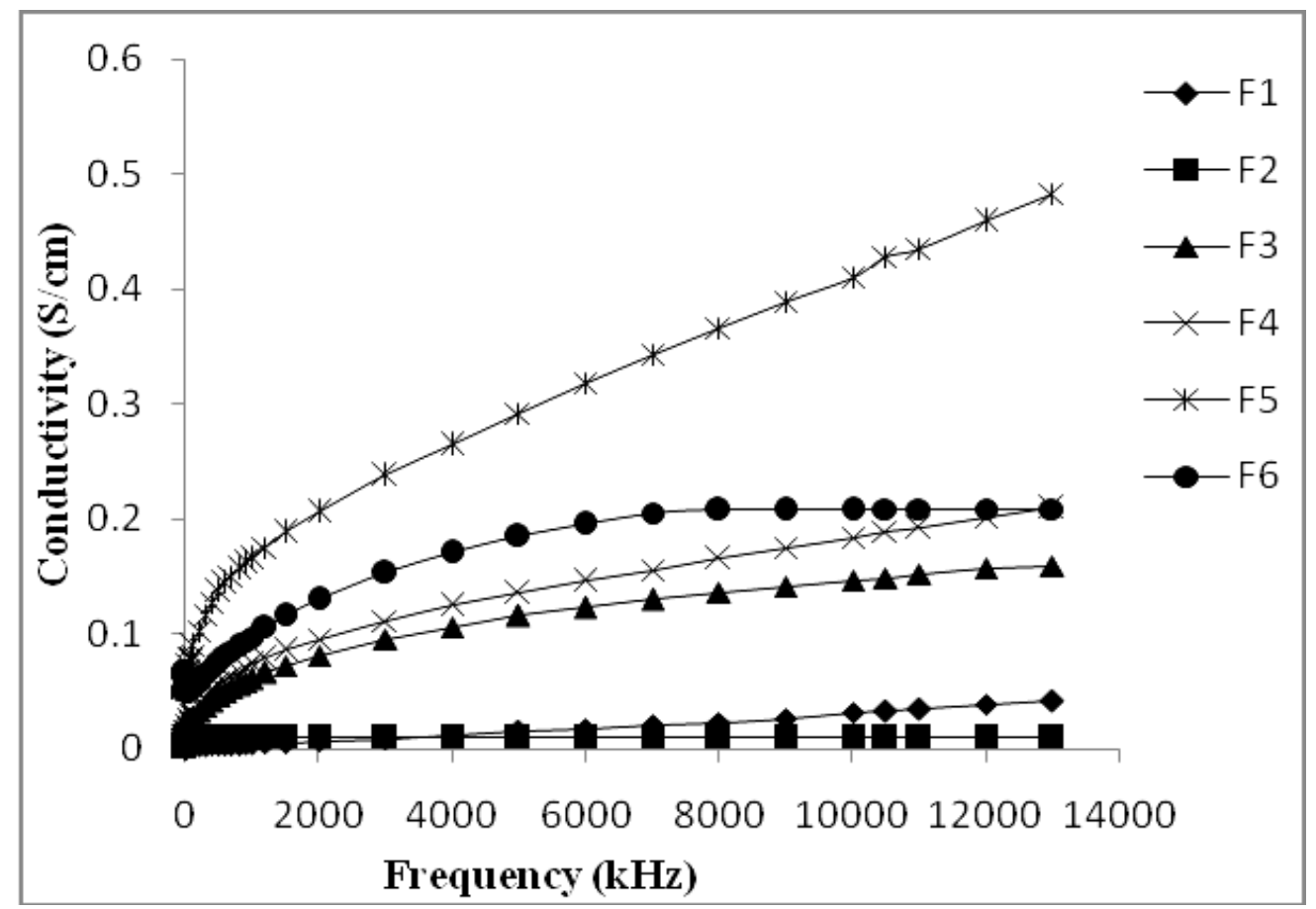

Fig. 2. Effect of sand content $(\% \mathrm{wt})$ on conductivity of sodium alginate $\left(\mathrm{TiO}_{2}\right)$ sand composite as a function of frequency. 
However, $6 \%$ sand containing composite films showed very significant improved level of conductivity in comparison with the other compositions.

\section{1. 2. I-V Characteristics}

The current-voltage $(\mathrm{I}-\mathrm{V})$ characteristics of Na-alginate $\left(\mathrm{TiO}_{2}\right)$ sand composites showed ohmic behavior. The current conduction increased rapidly for the sample containing higher percentage of sand as shown in Fig. 3. The maximum current conduction was observed for the sample containing $6 \%$ sand and it showed a linear trend of increase in current conduction with the applied voltage above $10 \mathrm{~V}$. So I-V characteristics of $6 \%$ sand containing composite film was well fitted to ohms law.

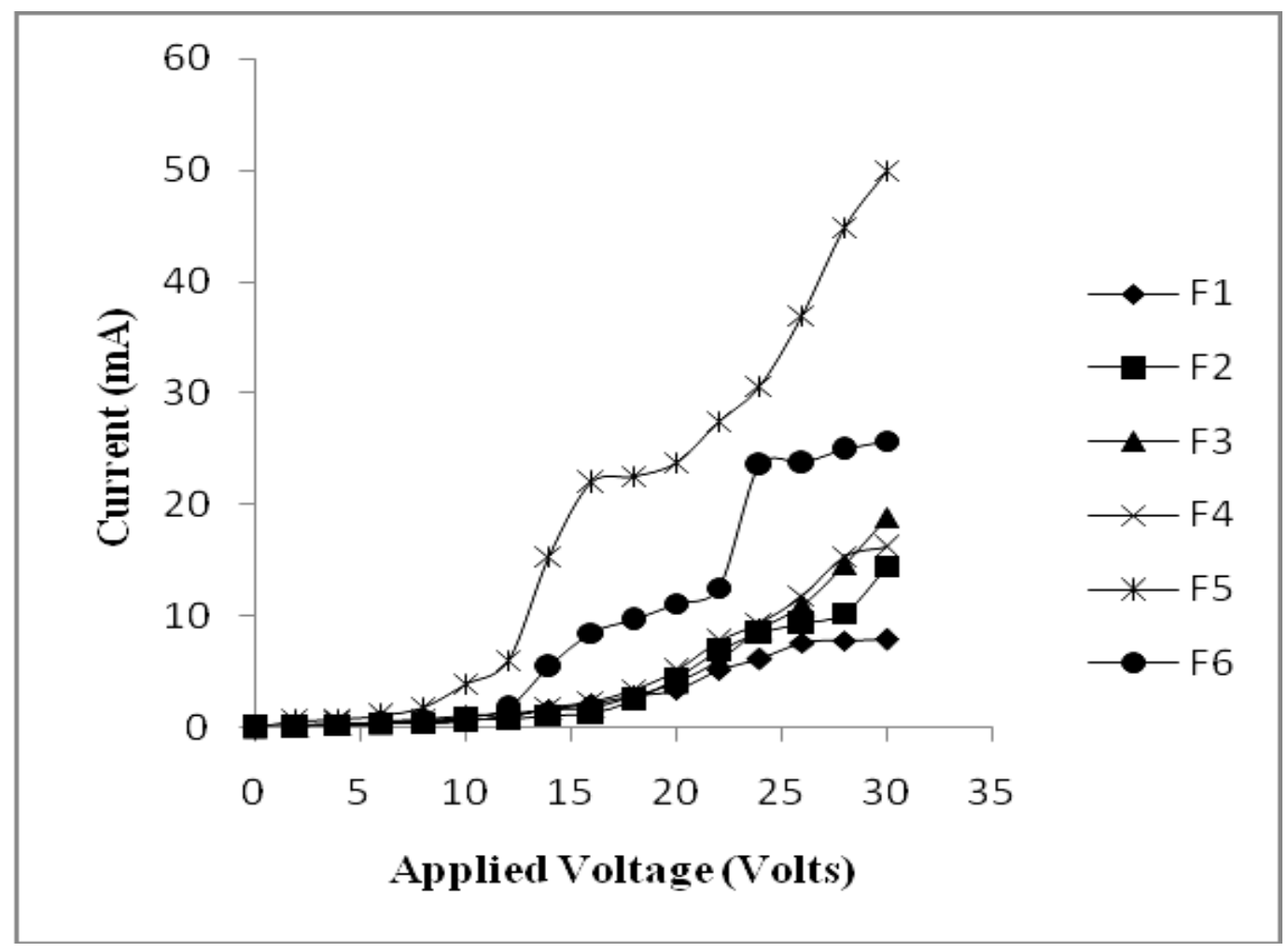

Fig. 3. I-V characteristics for different $\%$ wt of sand containing composite.

\section{1. 3. Dielectric Constant}

The study of dielectric constant of a material gives an outline about the nature of atoms, ions and their bonding in the material. The dielectric constant $\left(\varepsilon_{\mathrm{r}}\right)$ depends on frequency of the applied field. The dielectric constant $\left(\varepsilon_{\mathrm{r}}\right)$ showed a decreasing trend with increasing frequency of applied voltage as shown in the Fig. 4. The value of dielectric constant decrease as the frequency increases and it becomes independent at higher frequency region. The high value of dielectric constant in the low frequency region may be due to the contributions of electronic, ionic, dipolar, and space charge polarizations. The electronic exchange of the number of ions in the composite gives local displacement of electron in the direction of applied field, which in turn give rise to polarization. Generally, the polarizability $(\alpha)$ increases with increasing the dipolar moment, orientation and reorientation motion is due to the decrease of $\varepsilon_{\mathrm{r}}$ at higher 
frequency. From the experiment it is seen that $1 \%$ sand containing composite has the high value of dielectric constant and $0.1 \%$ composite has the lowest value.

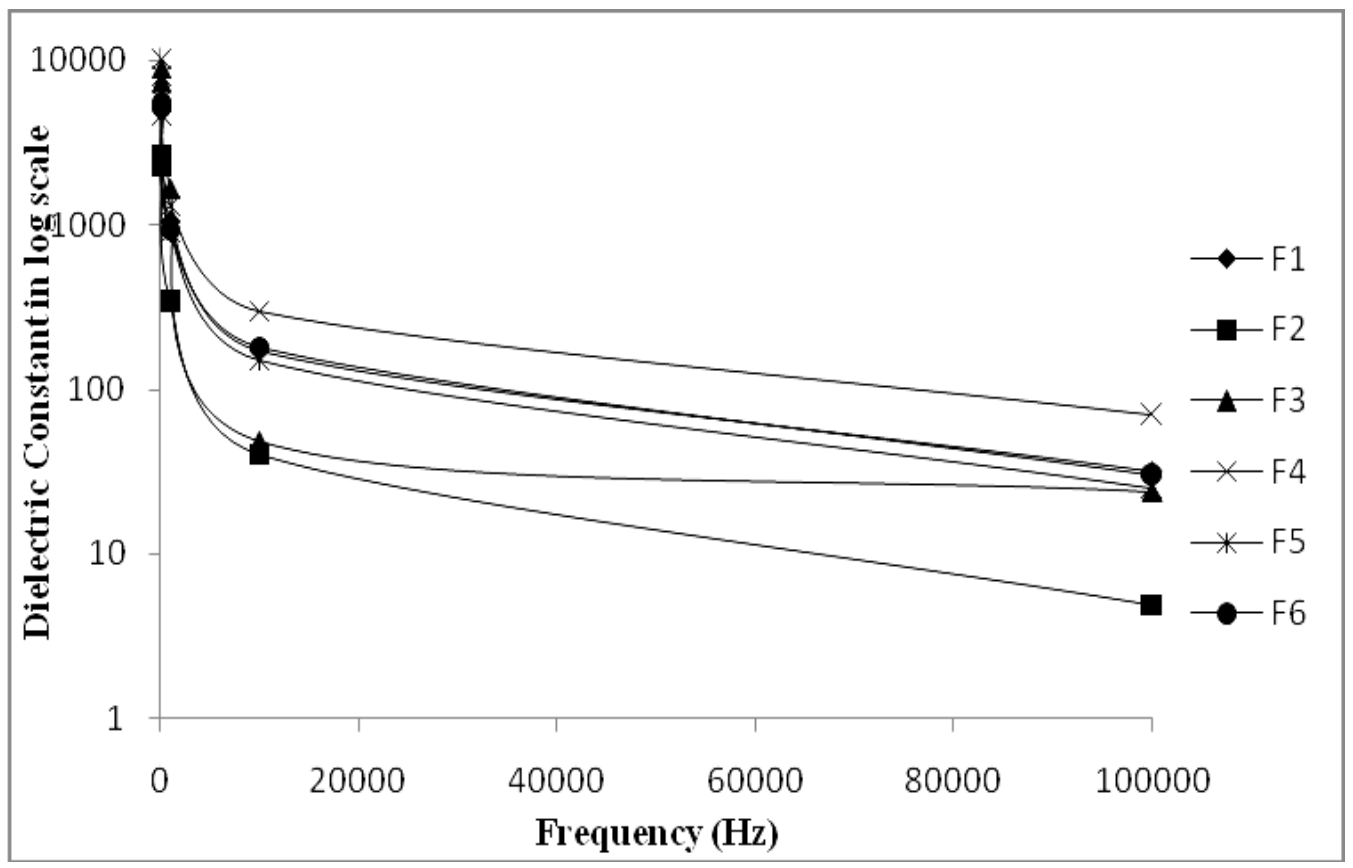

Fig. 4. Effect of sand (\% wt) on the dielectric constant as a function of frequency (Hz).

\section{1. 4. Loss Tangent}

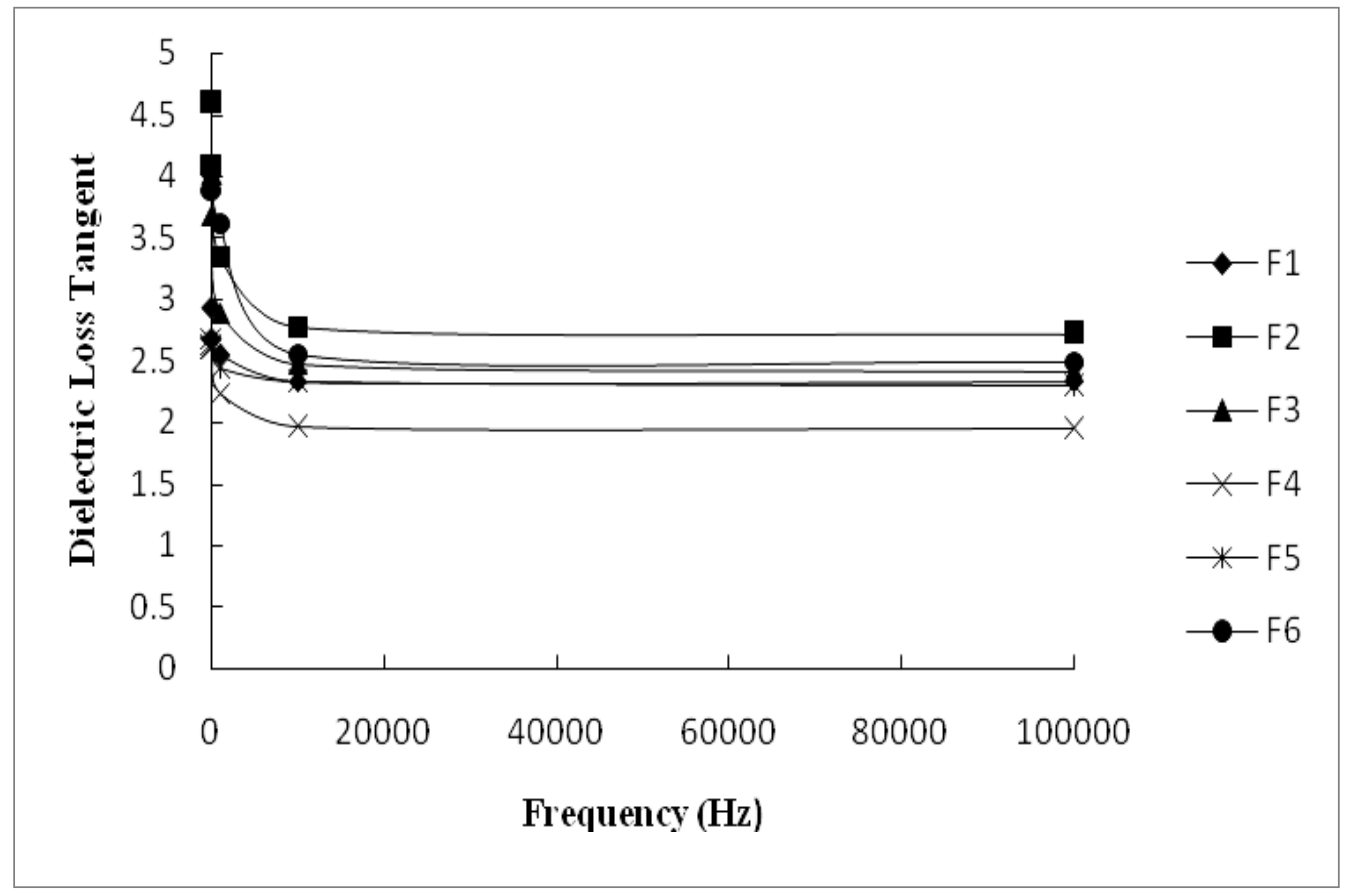

Fig. 5. Effect of frequency on dielectric loss tangent for different $\%$ wt of sand containing Naalginate $/ \mathrm{TiO}_{2} /$ Sand composite. 
Fig. 5 shows the variation of the dielectric loss $\left(\varepsilon^{\prime}\right)$ with frequency of applied field at room temperature. The behavior of variation is similar to that of dielectric constant with frequency. The dielectric loss is a measure of the energy absorbed by dielectric. Usually the dielectric has a resistance $\mathrm{R}$ and reactance $1 / \omega \mathrm{C}$. Which are related to the phase angle $\tan \delta=$ $1 / \omega \mathrm{CR}$, where $\mathrm{C}$ is the capacitance. So the low dielectric loss at high frequency region reveals the superior optical quality of the composite with lesser defects.

From this figure it is found that, dielectric loss decreases with increasing frequency due to the increase in the polarizability $(\alpha)$ by increasing the dipolar moment, orientation and reorientation motion and it lead to the decrease in dielectric loss at higher frequency. The similar behavior was seen in dielectric constant $\left(\varepsilon_{\mathrm{r}}\right)$. From figure it is also found that $1 \%$ Sand containing composite has the lowest loss factor and the $0.1 \%$ composite has maximum loss factor. Dielectric loss decreases drastically with increase in frequency until $10 \mathrm{kHz}$ and above $10 \mathrm{kHz}$ dielectric loss is almost constant.

\section{2. Mechanical Properties Studies}

The tensile strength of the films was increased with the increase in \%wt sand content shown in Fig. 6(a). The tensile strength of $0 \%$ composite film was found to be $0.541 \mathrm{MPa}$ and the highest tensile strength was $4.445 \mathrm{MPa}$ for $6 \%$ composite film among all the composite films used for this thesis. The tensile strength of the blend films began to decrease with the increase in \% wt of sand above $6 \%$.

Above $0.5 \%$ composite film elongation at break was being increased till $6 \%$ sand containing film and then decreases with the increase in sand content. The film containing $6 \%$ sand showed a very significant value of elongation at break.

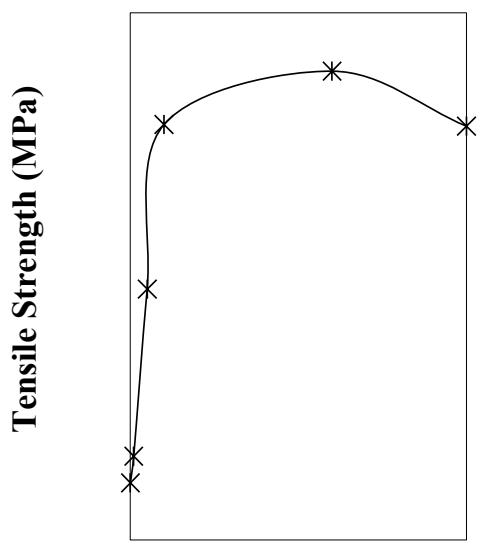

Composition (\% wt of
Sand)

(a)

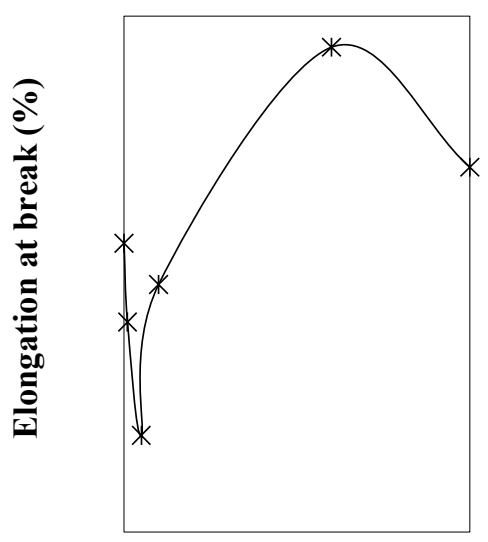

Composition ( \% wt of Sand)

(b)

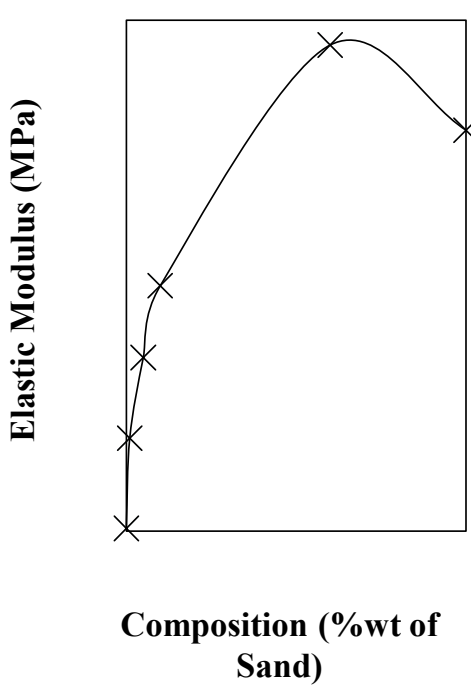

(c)

Fig. 6. Effect of sand on the (a) Tensile strength, (b) Elongation at break and (c) Elastic Modulus in Na-alginate $\left(\mathrm{TiO}_{2}\right)$ sand composite film.

The Young modulus of $38.17 \mathrm{MPa}$ was observed for the $0 \%$ sand containing composite film. It was also seen that with the incorporation of sand the Young modulus started to 
increase shown in Fig. 6(c). The $6 \%$ composite showed the highest elastic modulus of 72.8 $\mathrm{MPa}$. Further incorporation of sand in the composite the elastic modulus started to decrease.

\section{3. Water Uptake and Stability}

In Fig. 7(a) water uptake (\% wt) is plotted against soaking time. The highest water absorption of pure sodium alginate / $\mathrm{TiO}_{2}$ film was found to be $81.7293 \%$ at $80 \mathrm{sec}$. From the experiment it was found that the water absorption of the composites decreased gradually with the increase of the percentage of sand in composites and lowest water absorption was found for $6 \%$ sand containing composite film. This is most likely achieved by the reduction hydroxyl groups and introducing between sand and matrix because sand particle penetrates into the sodium alginate matrix and obstructs to create hydrogen bonding between Na-alginate and water molecules. But further incorporation of sand the water uptake tends to decrease.

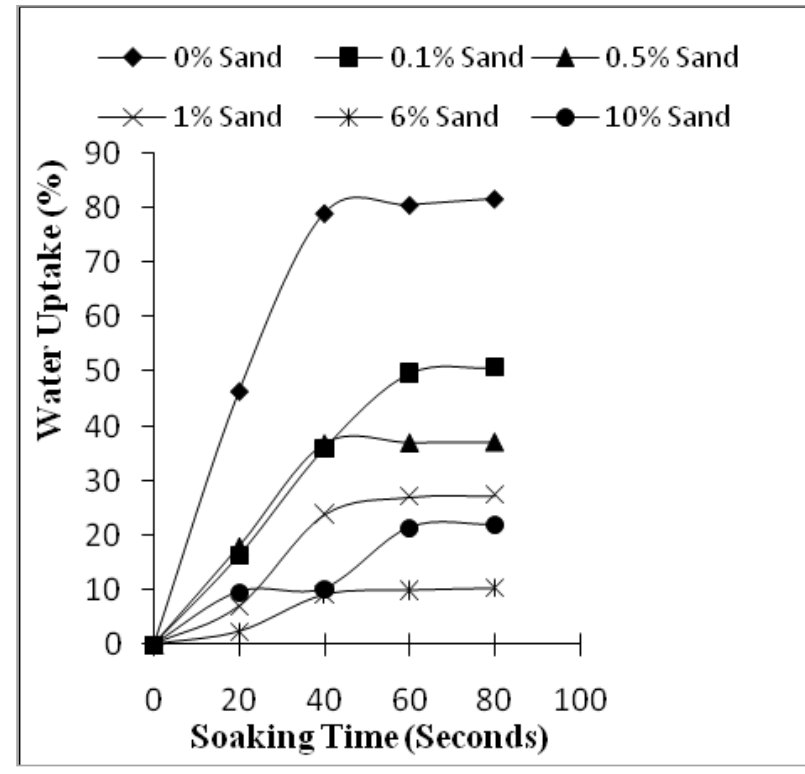

(a)

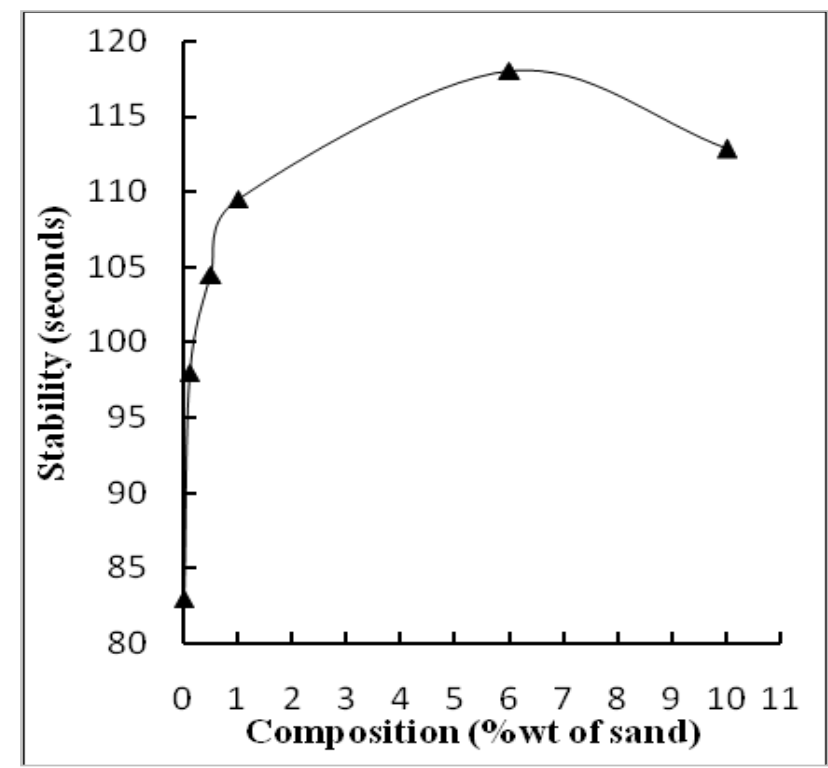

(b)

Fig. 7. Effect of sand on (a) water uptake and (b) stability of Na-alginate $/ \mathrm{TiO}_{2} / \mathrm{Sand}$ thin films. The stability of the composite films was increased with increasing sand content. Furthermore, Fig. 7 (b) also depicts that $6 \%$ sand containing Na-alginate $/ \mathrm{TiO}_{2}$ film has higher stability in water. The lower water uptake and higher stability is most likely due to the sufficient intermolecular hydrogen bonding between the hydrocarbon groups of Na-alginate and $\mathrm{SiO}_{2}$.

\section{CONCLUSION}

Sodium alginate $\left(\mathrm{TiO}_{2}\right)$ sand composite films of six different compositions have been fabricated using standard solution casting method. In this article, the effects of sand-addition on the electrical and mechanical properties of the composite films have studied thoroughly. Since organic polymer and water is poor conductor of electricity. The incorporation of sand could enhance the conductivity of the composite as semiconducting silicon atom is in sand. From the I-V characteristics it is clearly evident that the contact behavior is ohmic. Electrical properties of the composites were found to be improved due to better conjugation among sodium alginate, $\mathrm{TiO}_{2}$ and sand. The mechanical properties have been drastically improved 
due to sand content in the films. Due to the incorporation of sand the tensile strength and Young modulus of the composite has found to be increased. Also the elongation at break was decreased. The water resistance properties of the composites were improved with the incorporation of sand.

Throughout the investigation, it has been found that addition of sand remarkably improves the electrical and mechanical properties along with increased crosslinking. Even though, this work has some outstanding results which are very important in the field of electroactive natural polymer, it might have great potential application in the field of organic electronics especially in the field of organic semiconductor and organic photovoltaic solar cells. It might have an application in biosensors.

\section{ACKNOWLEDGEMENT}

This work was carried out in Institute of Radiation and Polymer Technology (IRPT) of Bangladesh Atomic Energy Research and Establishment (AERE), Department of Physics of Jahangirnagar University and Pilot Plant and Process Development Centre (PP \& PDC) of Bangladesh Council of Scientific and Industrial Research (BCSIR), Dhaka, Bangladesh.

\section{References}

[1] Lay G., Rehm J., Stepto R. F., Thoma M., Sachetto J., Lentz D. J., Silbiger J., U.S. Patent No. 5,095,054 (1992).

[2] Hamal D. B., Klabunde K. J., J. Colloid Interface Sci. 311 (2007) 514-522, http://dx.doi.org/10.1016/j.jcis.2007.03.001

[3] B. Tryba, A.W. Morawski, M. Inagaki, Appl. Catal. B: Environ. 46 (2003) 203-208, http://dx.doi.org/10.1016/S0926-3373(03)00214-5

[4] P. Chrysicopoulou, D. Davazoglou, Chr. Trapalis, G. Kordas, Thin Solid Films 323 (1998) 188-193, http://dx.doi.org/10.1016/S0040-6090(97)01018-3

[5] Lee J. W., Kong S., Kim W. S., and Kim J., Mater. Chem. Phys. 106 (2007) 39-44, http://dx.doi.org/10.1016/j.matchemphys.2007.05.019

[6] Wang W., Tao J., Wang T., Wang L., Rare Met. 26 (2007) 136-141, http://dx.doi.org/10.1016/S1001-0521(07)60173-9

[7] Doh J. G., Hong J. S., Vittal R., et al., Chem. Mater. 16 (2004) 493-497. doi: $10.1021 / \mathrm{cm} 030542 \mathrm{q}$

[8] Zhang D., Yoshida Y., Oekermann T., et al., Adv. Funct. Mater. 16 (2006) 1228-1234, doi:10.1002/adfm.200500700

[9] Rothschild, A., Edelman, F., Komem, Y., et al., Sensor Actuat., Ser. B, 67 (2000) 282-289, http://dx.doi.org/10.1016/S0925-4005(00)00523-2

[10] Shankar K., Tep K. C., Mor G. K., et al., J. Phys., Ser. D: Appl. Phys. 39 (2006) 2361-2366, doi:10.1088/0022-3727/39/11/008 
[11] Diebold U., Appl. Phys., Ser. A 76 (2003) 681-687, doi:10.1007/s00339-002-2004-5

[12] Choi S. Y., Mamak M., Speakman S., et al., Small 1 (2005) 226-232. doi:10.1002/smll.200400038

[13] Chu S. Z., Inoue S., Wada K., Li D., et al., Langmuir 21 (2005) 8035-8041, doi:10.1021/la050902j

[14] Kim K. D., Han D. N., Lee J. B., et al., Scrip. Mater. 54 (2006) 143-146, http://dx.doi.org/10.1016/j.scriptamat.2005.09.054

[15] Wang H., Lewis J. P., J. Phys., Ser. C 17 (2006) L 209-213, doi:10.1088/0953-8984/17/21/L01

[16] Pan J. H., Lee W. I., Chem. Mater. 18 (2006) 847-853, doi:10.1021/cm0522782

[17] Bavykin D. V., Friedrich J. M., Walsh F. C., Adv. Mater. 18 (2006) 2807-2824, doi:10.1002/adma.200502696

[18] Standard Methods for the Sampling and Testing of Gelatins, Gelatin Manufacturers Institute of America, Inc., 501 fifth Ave., Room 1015, New York, NY.

[19] Ali A., Studies on the Degradation of Jute fibre, An M.Sc. Thesis, Rajshahi University, Rajshahi, Bangladesh, 66 (1987) 29-31.

[20] Leach D. C., Mechanical \& Fire Properties of APC-2 Presented at SAMPLE at Albuqueeque, 1987, 9-11.

[21] Bipasha Bose, Effect of water absorption on the mechanical properties of jute fiber reinforced polymer composites, 2005.

[22] ASTM Designation: D570-81, Standard Test Method for water absorption of plastic, 1988, 141-143.

[23] Farnades F. N., Riz A. I., Garder M., Aranda P., Ruiz-Hitzky E., Journal of Nanoscience and Nanotechnology, in press 2008.

[24] Caio M. Paranhos, G. Bluma Soares, et al, Macromol. Mater. Eng. 292 (2007) 620-626.

[25] Zanetti M., Lomakin S., Camino G., Macromal. Mater. Eng. 279 (2000) 1-9, doi:10.1002/1439-2054(20000601)279:1<1::AID-MAME1>3.0.CO;2-Q 